\title{
Assessment of the attitude towards Plagiarism among dental postgraduate students and faculty members in Bapuji Dental College and Hospital, Davangere - A cross sectional survey
}

\author{
Dr. Mary Shimi S. Gomez, Dr. Nagesh L., Dr. Sujatha B.K.
}

\begin{abstract}
:
Objectives: To assess the attitude of dental postgraduate students and faculty members towards plagiarism in Bapuji Dental College and Hospital, Davangere.

Materials and methods: A closed ended, standard questionnaire containing 29 statements on a 5 point Likert scale for each statement was used to collect data which measures three attitudinal factors (positive and negative attitude and subjective norms) towards plagiarism. The positive attitude towards plagiarism reflects approval and justification of such behaviour. Negative attitude towards plagiarism expresses condemnation and disapproval of plagiarism. Subjective norm expresses common thinking about the prevalence of plagiarism and the acceptance of such behaviour in the academic and scientific communities.

Results: with respect to dental postgraduate students, the mean of the scores for the questions under: positive

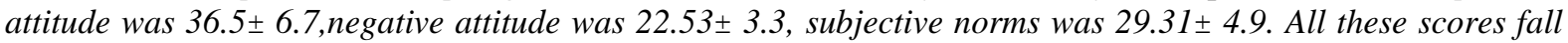
under moderate category. With respect to the faculty members mean of the scores of the questions under:

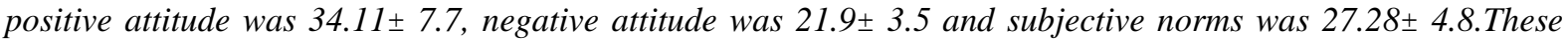
values also fall under moderate category.

Conclusions: The attitude of the postgraduate students and faculty member reflect insufficient level of seriousness and awareness with which plagiarism is perceived. Awareness about plagiarism should be improved among postgraduate students and faculty members.
\end{abstract}

Keywords: Plagiarism, dental postgraduate students, faculty members, scientific misconduct

\section{Introduction}

Scientific and professional work in the field of biomedicine requires great responsibility, total commitment and serious and honest lifetime work and learning. According to Robert Merton, an ideal quality of a scientist is to have a passion for the truth. ${ }^{1}$ Patients benefit not only from good quality care but also from good scientific research. We all expect high standards of scientific and medical research practice. ${ }^{2}$ Science, after all, is a search for the truth. ${ }^{3}$ The integrity, skills, trustworthiness and truthfulness of the scientific researchers are essential in order to gain the confidence of the public. ${ }^{2}$

Scientific misconduct has been the focus of interest in the recent years. Research misconduct usually includes fabrication, falsification, plagiarism, and other unethical behaviour in professional scientific research. Out of these, plagiarism is the most frequent type of misconduct. Plagiarism is defined as unauthorised appropriation of another's work, ideas, methods, results or words without acknowledging the source and original author. ${ }^{4}$

The prevalence of plagiarism has been increasing in the recent years. There are many reasons which can be attributed to the increased motivation towards plagiarism. The first and foremost is the wealth of information which could be accessed at our fingertips through the internet facility. ${ }^{5}$ This easy access has made the copy and paste technique to become more widely used in order to copy the ideas, words and works of others into one's own research work.

Another reason which could initiate the researcher to the conduct of plagiarism is the pressure within oneself to increase the number of publications as a credit of his own. The focus of the professional regulation body and also the peer review board on the number of publications also has added to the reasons. Thus quantity of work increased but not the quality. ${ }^{5}$ Another motivation for plagiarism could be the English language as the second language. Even though English is an international language, many do not find it comfortable to write in this language. ${ }^{4}$ Thus, increasing the prevalence of copy and paste technique from other studies into their own without giving any credit to the original author. Therefore, successful policy has to be developed for preventing and reducing plagiarism.

As postgraduates and the faculty will be conducting researches as part of their curriculum and profession, an attempt was made to explore the literature regarding the attitude of the dental postgraduate students and faculty members towards plagiarism. As exploration of the available literature reveals no studies in relation to the assessment of attitude towards plagiarism among dental postgraduate students and faculty 
members, a study is conducted to explore the same among dental postgraduate students and faculty members in Bapuji dental College and Hospital, Davangere.

\section{Materials And Methods}

The present study is a cross-sectional survey conducted in an institutional setting. All postgraduate students and faculty members of Bapuji Dental College and Hospital were included in the present study.

Ethical consent for the present study was obtained from the Institutional Review Board of Bapuji Dental College and Hospital, Davangere, Karnataka. The required permission to conduct the study was obtained from the concerned authorities. Written informed consent and voluntary consent was obtained from the participants after explaining the purpose of the study.

The questionnaire was self administered to all the dental post graduate students (140) and faculty members (51) in Bapuji dental college and Hospital, Davangere during the clinical hours in college. All participants were given the instructions for answering the questionnaire printed on the paper. The questionnaire is a closed ended, standard questionnaire containing 29 statements on a 5 point Likert scale (graded 1 - strongly disagree, 2 - disagree, 3 - neither agree nor disagree, 4 - agree and 5 - strongly agree) for each statement. According to that scale, points were designated to each answer. Positive attitude is measured by 12 statements with score range 12-60. Low score range (12-28) will indicate attitude with low tolerance toward plagiarism. Negative attitude is measured by 7 statements with score ranging 7-35. In this attitudinal factor high score range: $27-35$, indicates attitude with no tolerance of plagiarism. Subjective norms are measured by 10 statements with score ranging 10-50. With low subjective norms toward plagiarism, participants will consider such behaviour unacceptable in society and thus low score (scored 10-23) will be favourable. All the questions under each attitudinal factor were haphazardly arranged in order to avoid response bias.

The scores for the questions under positive, negative and subjective norms were summed up separately. Then the mean of the scores for the questions under each category was calculated separately for postgraduate students and faculty members. To measure the attitudinal factors, these scores were compared with the reference scores. ${ }^{6}$

The data obtained was compiled systematically in Microsoft Excel sheet and subjected to statistical analysis to assess the attitude towards plagiarism among dental postgraduate students and faculty members in Bapuji Dental College and Hospital, Davangere using Chi -square test.

\section{Results:}

The results were presented as score (mean $\pm \mathrm{SD}$ ) followed by reference range (divided in three equal parts: low, moderate, high score).

The score range for the questions under positive attitude (favouring plagiarism) is: 12-60

low: $12-28$

moderate: $29-45$

high: 46-60

The score range for the questions under negative attitude (disfavouring plagiarism): 7-35

low: $7-16$

moderate: $17-26$

high: $27-35$

The score range for the questions under subjective norms (how they perceive plagiarism in the environment): $10-50$

low: $10-23$

moderate: $24-37$

high: $38-50$

In the present study with respect to dental postgraduate students the mean of the scores for the questions under positive attitude was $36.5 \pm 6.7$, negative attitude was $22.53 \pm 3.3$, subjective norms was $29.31 \pm$ 4.9. All these scores fall under moderate category. With respect to the faculty members mean of the scores for the questions under: positive attitude was $34.11 \pm 7.7$, negative attitude was $21.9 \pm 3.5$ and subjective norms was 27.28 4.8.These values also fall under moderate category.

\section{Discussion:}

Scientific misconduct is usually recognized as fabrication and falsification of data and plagiarism. Scientific misconduct has been the focus of interest in the recent years. Out of these, plagiarism is the most frequent type of misconduct. In the present study the participants, postgraduate students and faculty members were found to have moderate attitude towards plagiarism. The results of the present study are consistent with 
that of the study conducted by Pupovac V et al. ${ }^{6}$ Exploration of the available literature revealed no Indian studies that were conducted to assess the attitude towards plagiarism among dental postgraduate students and faculty members. Thus, these particular groups were selected as the postgraduates and the faculty will be conducting researches as part of their curriculum and profession.

In the present study $42 \%$ of postgraduate students and $47 \%$ of faculty members agreed that selfplagiarism is not punishable because it is not harmful. $31 \%$ of postgraduate students and $25 \%$ of faculty members agreed to the statement saying short deadlines give me the right to plagiarize a bit, but $41 \%$ of postgraduate students and $47 \%$ of faculty members disagreed for the same. For the statement, young researchers who are just learning the ropes should receive milder punishment for plagiarism, $43 \%$ of postgraduate students and $39 \%$ of faculty members agreed. $48 \%$ of postgraduate students and $35 \%$ of faculty members disagreed for the statement if one cannot write well in a foreign language (e.g., English), it is justified to copy parts of a similar paper already published in that language. $42 \%$ of postgraduate students and $52 \%$ of faculty members disagreed for the statement saying could not write a scientific paper without plagiarizing. These statements show that majority of the postgraduate students and faculty members are supporting plagiarism with very few disagreeing to the statements favouring plagiarism. For the statement, Plagiarism impoverishes the investigative spirit $56 \%$ of postgraduate students and $21 \%$ of faculty members agreed thus showing that they are disfavoring plagiarism. $51 \%$ of postgraduate students and $41 \%$ of faculty members disagreed for the statement I work (study) in a plagiarism-free environment shows that plagiarism is commonly practiced method in scientific writing.

What would normally we viewed in scientific settings as unacceptable were viewed as acceptable by a substantial proportion of postgraduate students and faculty members. Overall the results suggest a disturbing lack of understanding of basic elements of scientific writing. If this situation continues research becomes mere duplication of earlier studies and suffers from lack of originality. In the present study we have selected a convenient sample. Thus further researches should be conducted on large scale for generalizability. We recommend that the peer review board should be equipped with software to detect plagiarism. The university should come up with rules and regulations to prevent plagiarism and also installing software to detect plagiarism in the work submitted by the students as well as faculty members. A committee should be established in the respective institutions to detect plagiarism.

\section{Conclusions:}

The attitude of the postgraduate students and the faculty members reflect insufficient level of seriousness and awareness with which plagiarism if perceived. Awareness about plagiarism should be improved among postgraduate students and faculty members. Strict rules should be set by the university to prevent the plagiarism.

\section{Acknowledgement}

We thank all the postgraduate students and faculty members of Bapuji Dental College and Hospital, Davangere for their participation and co-operation throughout the study.

\section{References}

[1]. Lynoe N., Jacobsson L., and Lundgren E. Fraud, misconduct or normal science in medical research - an empirical study of demarcation. J Med Ethics 1999;25:501-506.

[2]. http://www.rcpe.ac.uk/clinicalstandards/standards/misconduct_99.php accessed on 29-8-2011.

[3]. Douglas L. Preventing scientific misconduct. Am J Public Health 1998; 88(1): 125-129.

[4]. Mavrinac M., Brumini G., Bilić-Zulle L., Petrovečki M. Construction and Validation of Attitudes towards Plagiarism Questionnaire. Croat Med J. 2010; 51: 195-201.

[5]. Reddy S. Greetings from Davangere, Karnataka, India: searching versus researching. J Indian Soc Pedod Prev Dent 2011; $29(1): 1$.

[6]. Pupovac V., Bilic-Zulle L., Mavrinac M., Petrovecki M. Attitudes toward plagiarism among pharmacy and medical biochemistry students - cross-sectional survey study. Biochemia Medica 2010;20(3):307-13.

Table 1. Statements describing positive attitude

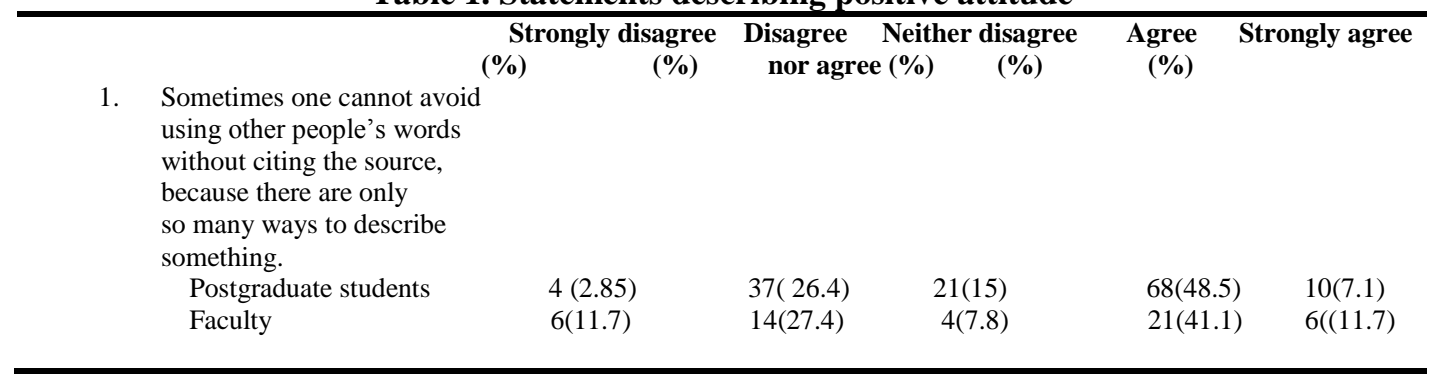


2. When I do not know what to

write, I translate a part of a paper

from a foreign language.

$\begin{array}{llllll}\text { Postgraduate students } & 23(16.4) & 54(38.5) & 19(13.5) & 40(28.5) & 4(2.8) \\ \text { Faculty } & 8(15.6) & 23(45) & 4(7.8) & 15(29.4) & 1(1.9)\end{array}$

3. Self-plagiarism is not punishable

because it is not harmful

(one cannot steal from oneself). Postgraduate students Faculty

4. Short deadlines give me the right to plagiarize a bit.

Postgraduate student

Faculty

15(10.7) 58(41.4)

10(19.6) 24(47)

$\begin{array}{lll}16(11.4) & 44(31.4) & 7(5) \\ 4(7.8) & 13(25.4) & 0(0)\end{array}$

5. Self-plagiarism should not be punishable as plagiarism.

Postgraduate students

\section{Strongly disagree}

Disagree Neither disagree

Agree Strongly agree

6. It is justified to use

one's own previously

published work without

providing citation in

order to complete the

current work.

Postgraduate students

$15(10.7)$

$70(50)$

19(37.2)

14((10)

33(23.5)

$8(5.7)$

Faculty

7. Young researchers who

are just learning the ropes

should receive milder

punishment for plagiarism.

Postgraduate students

8. It is justified to use previous descriptions of a method, because the method itself remains the same.

Postgraduate students

9. If one cannot write well in a foreign language (e.g., English), it is justified to copy parts of a similar paper already published in that language

$\begin{array}{llllll}\text { Postgraduate students } & 19(13.5) & 68(48.5) & 19(13.5) & 32(22.8) & 2(1.4) \\ \text { Faculty } & 11(21.5) & 18(35.2) & 10(19.6) & 11(21.5) & 1(1.9)\end{array}$

10. If a colleague of mine allows

Me to copy from her/his paper,

I am not doing anything bad,

because I have his/her permission. Postgraduate students

11. Plagiarized parts of a paper may

be ignored if the paper

is of great scientific value.

Postgraduate students

Faculty

12. Could not write a scientific paper without plagiarizing. 


\begin{tabular}{cccccc}
\hline Faculty & $12(23.5)$ & $27(52.9)$ & $5(9.8)$ & $7(13.7)$ & $0(0)$ \\
\hline
\end{tabular}

Table 2. Statements describing negative attitude

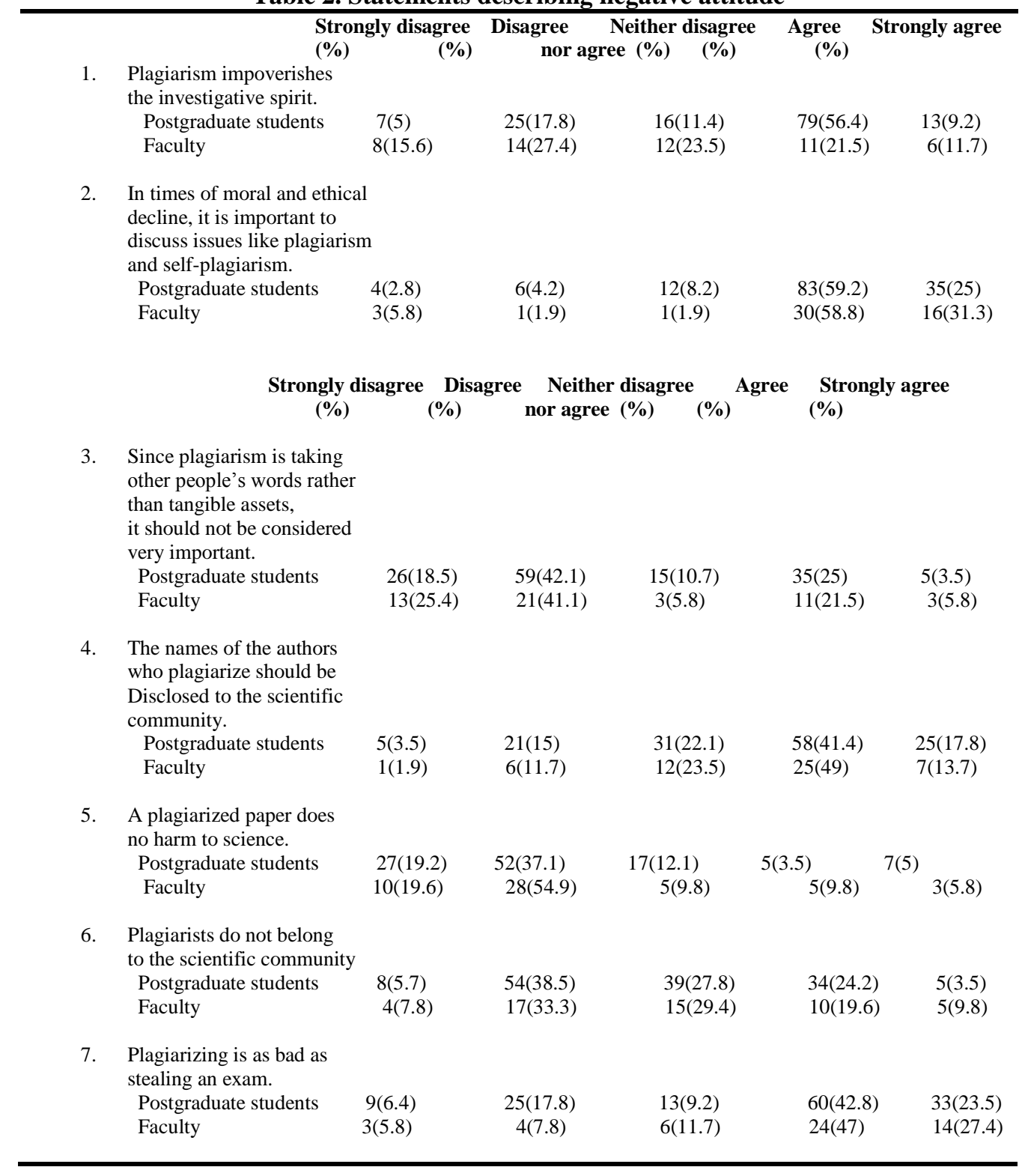

Table 3. Statements describing subjective norms

\begin{tabular}{|c|c|c|c|c|c|c|}
\hline & & Strongly disagree & e Disagree & Neither disag & ree Agree & Strongly agree \\
\hline 1. & $\begin{array}{l}\text { Those who say they have ne } \\
\text { plagiarized are lying. } \\
\text { Postgraduate students } \\
\text { Faculty }\end{array}$ & $\begin{array}{l}\text { ever } \\
\qquad 5(3.5) \\
2(3.9)\end{array}$ & $\begin{array}{l}11(7.8) \\
4(7.8)\end{array}$ & $\begin{array}{c}34(24.2) \\
14(27.4)\end{array}$ & $\begin{array}{l}67(47.8) \\
24(47)\end{array}$ & $\begin{array}{c}23(16.4) \\
7(13.7)\end{array}$ \\
\hline 2. & $\begin{array}{l}\text { Sometimes I copy a sentence } \\
\text { or two just to become } \\
\text { inspired for further writing. } \\
\text { Postgraduate students } \\
\text { Faculty }\end{array}$ & $\begin{array}{l}4(2.8) \\
3(5.8)\end{array}$ & $\begin{array}{l}30(21.4) \\
11(21.5)\end{array}$ & $\begin{array}{l}19(13.5) \\
9(17.6)\end{array}$ & $\begin{array}{l}78(55.7) \\
26(50.9)\end{array}$ & $\begin{array}{l}9(6.4) \\
2(3.9)\end{array}$ \\
\hline 3. & $\begin{array}{l}\text { Authors say they do not } \\
\text { plagiarize, when in fact they } \\
\text { Postgraduate students } \\
\text { Faculty }\end{array}$ & $\begin{array}{l}\text { do. } \\
2(3.9)\end{array}$ & $\begin{array}{l}10(7.1) \\
2(3.9)\end{array}$ & $\begin{array}{c}25(17.8) \\
12(23.5)\end{array}$ & $\begin{array}{l}82(58.5) \\
25(49)\end{array}$ & $\begin{array}{l}23(16.4) \\
5(9.8)\end{array}$ \\
\hline
\end{tabular}


4. I do not have bad conscience

for copying verbatim a

sentence or two from my

previous papers.

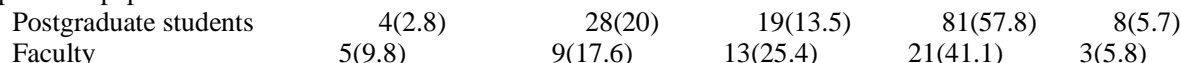

$\begin{array}{lllll}\text { Faculty } & 5(9.8) & 9(17.6) & 13(25.4) & 21(41.1)\end{array}$

5. Sometimes I am tempted to

plagiarize, because

everyone else is doing it

(students, researchers,

physicians).

Postgraduate students

Faculty

$31(22.1)$

46(32.8) 18(12.8)

44(31.4) $\quad 1(0.7)$

$17(33.3)$

$20(39.2)$

2(3.9)

$11(21.5)$

$1(1.9)$

6. It is not so bad to plagiarize.

Postgraduate students

$14(10)$

$66(47.1)$

27(19.2) 30(21.4)

21(41.1) 9(17.6) 7(13.7)

$3(2.1)$

Faculty

14(27.4)

Disagree Neither disagree

Strongly disagree

(\%)

nor agree $(\%)$

(\%)

Agree Strongly agree

(\%)

$(\%)$

7. I work (study) in a

plagiarism-free

environment.

Postgraduate student

21(15) 72(51.4)

25(17.8)

$18(12.8)$

$4(2.8)$

Faculty

6(11.7) 21(41.1)

13(25.4)

11(21.5)

$0(0)$

8. Sometimes, it is necessary

to plagiarize

Postgraduate students

9(6.4) 36(25.7)

28(20)

60(42.8) 7(5)

Faculty

$6(11.7 \quad 19(37.2)$

11(21.5)

14(27.4) 1(1.9)

9. Plagiarism is justified if I

currently have more important

obligations or tasks to do.

Postgraduate students
Faculty

23(16.4) 69(49.2)

$15(10.7)$

$33(23.5)$

$5(9.8)$

$0(0)$

10(19.6) 26(50.9)

9(17.6)

1(1.9)

10. I keep plagiarizing because

I haven't been caught yet.

Postgraduate students

39(27.8) $\quad 84(60)$

9(6.4)

$3(0.7)$

$5(3.5)$

Faculty

17(33.3) 28(54.9)

4(7.8)

2(3.9)

$0(0)$ 